\title{
Experimental and Numerical Investigation of Load Failure at the Interface Joint of Repaired Potholes Using Hot Mix Asphalt with Steel Fiber Additive
}

\author{
Mohamed S. Eisa ${ }^{1, *(D)}$, Fahmy S. Abdelhaleem ${ }^{1}$ and Vivian A. Khater ${ }^{2}$ \\ 1 Civil Engineering Department, Faculty of Engineering, Benha University, New Benha 13512, Egypt; \\ fahmy.hri@bhit.bu.edu.eg \\ 2 Civil Engineering Department, Higher Institute of Engineering and Technology, Menoufia 32511, Egypt; \\ viviankhater2013@yahoo.com \\ * Correspondence: mohamedeisa524@bhit.bu.edu.eg
}

Citation: Eisa, M.S.; Abdelhaleem, F.S.;

Khater, V.A. Experimental and

Numerical Investigation of Load

Failure at the Interface Joint of

Repaired Potholes Using Hot Mix

Asphalt with Steel Fiber Additive.

Coatings 2021, 11, 1160. https://

doi.org/10.3390/coatings11101160

Academic Editor: Giuseppe Cantisani

Received: 6 August 2021

Accepted: 21 September 2021

Published: 26 September 2021

Publisher's Note: MDPI stays neutral with regard to jurisdictional claims in published maps and institutional affiliations.

Copyright: (c) 2021 by the authors. Licensee MDPI, Basel, Switzerland. This article is an open access article distributed under the terms and conditions of the Creative Commons Attribution (CC BY) license (https:// creativecommons.org/licenses/by/ $4.0 /)$.

\begin{abstract}
The maintenance of potholes is a long-standing problem. Previous studies focused on pothole patching materials and methods but not on bonding at the interface joint. In this study, the influence of the patching shape and depth on the bonding at the interface joint using two patching materials: hot mix asphalt (HMA) and hot mix asphalt containing $5 \%$ (by volume) steel fiber (HMA + ) was investigated. Slabs with circular and square potholes in the middle with different depths $(35,50$ and $70 \mathrm{~mm}$ ) were prepared. The two shapes of potholes were patched with two patching materials: HMA and HMA+, at different depths. The slabs were tested after patching using a rigid steel frame. The experimental results were compared with those obtained from finite element analysis using the ABAQUS software, applying the same model of slabs with the same dimensions and properties of the materials used. The results indicated that the bonding at joint interface for circular-patched potholes slightly improved using HMA+ and this was independent of patching depth. As for the square-patched potholes, the bonding at the interface joint was better than for the circular-patched ones; the bonding increased with increasing depth. Using HMA+ for patching the square-patched potholes, the bonding at the interface joint slightly increased, only for the $3.5 \mathrm{~cm}$ depth.
\end{abstract}

Keywords: pothole maintenance; circular potholes; square potholes; hot mix asphalt; steel fiber; ABAQUS; bonding at the interface joint

\section{Introduction}

Road and highway pavement infrastructure are crucial for national economies and societies as they ease transportation and the connections between communities. Road paving materials like asphalt and concrete are prone to deteriorations due to environmental and traffic factors [1]. The most common form of these deteriorations are potholes, which pose risks to vehicles and people [2]. The maintenance of potholes is an expensive process. Reports from the USA and UK indicate that large budgets are spent on the repair of potholes [3,4]. If potholes are not repaired at early stages of formation, more severe structural failure may occur due to water interaction with the subgrade [5].

The cost of maintenance and pavement durability are influenced by the selection of appropriate method and patching material [6]. Hot mix asphalt (HMA) and cold mix asphalt (CMA) are widely used as patching materials. Although HMA is of a high quality, it is energy-consuming and consequently expensive. On the contrary, CMA has a lower impact on energy consumption and environmental pollution but its mechanical performance is poorer $[1,6]$. Several properties are taken into consideration when repairing potholes in choosing the patching material, such as workability, cohesion, traffic loading, environmental durability, bonding, freeze-thaw and rutting potential [7]. Kwon et al. investigated reclaimed asphalt pavement as a patching material for pothole repair using 
the spray injection method, because it showed better stability and adhesion compared to the virgin aggregate [2]. Li et al. produced thermal asphalt mortar and concrete for pothole maintenance with favorable bond strength, rutting and cracking resistance due to higher thermal conductivity [8]. Liu et al. suggested a new polymer-modified asphalt based on microcapsules and polymer reinforcement techniques for cold mixtures, to be used in potholes patching in cold and rainy weather. Tests showed that the polymer-modified asphalt mixtures were better than terpene resin cutback asphalt with respect to cohesion, stability and freeze-thaw resistance [9].

Regarding methods of maintenance, several are used, with varying pros and cons. The throw-and-roll method is a cost-effective, rapid method but is temporary and less durable than other methods $[10,11]$. Though the semi-permanent method saves time and effort, it needs more equipment and labor $[6,11,12]$. Other methods, like inlay/overlay or hot-on-hot paving processes are costly, energy-consuming and hazardous for workers and the environment [13]. New methods have been proposed, using the induction heating of asphalt tiles surrounded by metal particles or pellets containing metal particles and an electromagnetic field. The resulting road was more durable than the roads repaired using current techniques $[14,15]$. The low service life of traditional pothole maintenance methods is a result of the disadvantages of cold joints, the weak bonding between the old and new materials at the joint, the difficult compaction of the new material and large porosity and easy water seepage [16].

The previously mentioned studies issued pothole patching materials and methods rather than the treatment of the interface between the old and new pavement parts in repairing potholes. It was found that the stability of the interface joint between the new and old pavement parts should be guaranteed to ensure the performance of pothole repair [17]. Dry maintenance of interface joints is proven to increase the service life of repaired potholes [18]. It is evident that the joints between old and new pavement parts play the most important role in the durability and service life of repaired potholes. Although the previous studies investigated potholes and interface problem, few studies assessed the performance of the joints between the new and old parts of asphalt pavement in potholes. Li et al. investigated the bond strength and fatigue life of different forms of interface joints for asphalt pavement pothole repair. They found that the bond strength and fatigue life of high viscoelastic emulsified asphalt with an area density of $0.6 \mathrm{~kg} / \mathrm{m}^{2}$ in the form of a $30^{\circ}$ inclination joint were higher than those of traditional pothole repair [19].

Steel fibers are used as asphalt concrete mixtures additives as they have been demonstrated to bear stresses at the surface and increase stability by decreasing the amount of gaps in the mixture, if used in appropriate amounts and specifications for the fiber [20]. Additionally, they may be used in the binder course to avoid damage from vehicle tires [21]. The purpose of this paper is to investigate the influence of steel fiber additive to the patching material of potholes, and the patching shape (circular and square) on the bond between new and old pavement parts as they affect the service performance and life of pothole repairs. The bond strength and fatigue behavior of joints are used to evaluate the effectiveness of pothole repairs under various conditions. Rigid steel loading frame tests were conducted as laboratory tests and the effects of several parameters, including patching shape and percent of steel fiber were investigated. Moreover, the experiments were complemented by finite element analysis (FEA) using ABAQUS software V.6.14.

\section{Materials and Methods}

\subsection{Materials}

The materials used in this research are divided into two types: surface materials and subbase materials.

\subsubsection{Surface Materials}

As a base for this study, a reference hot asphalt concrete mix was designed. The asphaltic concrete mixes tested in this study are composed of optimum bitumen content 
(with $20 \%$ air void content and composed of optimum bitumen content (5.5\%), 55\% coarse aggregate, $15 \%$ natural sand, $25 \%$ crushed sand, and $5.0 \%$ lime stone dust as a control mineral filler). The gradation of the reference mixture lies within the limits of Egyptian standard specifications for binder course mix (Mix 4C) [22]. Table 1 presents the gradation of the used mix.

Table 1. The gradation of the used mix and specification limits.

\begin{tabular}{ccc}
\hline Sieve Size & Gradations of Used Mix & Specification Limits (4C) \\
\cline { 1 - 2 } In & & \\
\hline 1 & 100.0 & 100 \\
$3 / 4^{\prime \prime}$ & 96.1 & $80-100$ \\
$1 / 2^{\prime \prime}$ & 83.0 & - \\
$3 / 8^{\prime \prime}$ & 67.3 & $60-80$ \\
No. 4 & 59.0 & $48-65$ \\
No. 8 & 40.7 & $35-50$ \\
No. 30 & 25.3 & $19-30$ \\
No. 50 & 15.6 & $23-13$ \\
No. 100 & 11.5 & $7-15$ \\
No. 200 & 7.5 & $2-8$ \\
\hline
\end{tabular}

Crushed dolomite stone obtained from Ataka Quarry, Suez Governorate (Suez, Egypt) was used as the coarse aggregate portion in the asphalt concrete mixtures. The properties of the aggregate used, according to the Egyptian specification of asphalt concrete [22], are shown in Table 2.

Table 2. Properties of aggregate used.

\begin{tabular}{ccccc}
\hline Test No. & Test & $\begin{array}{c}\text { AASHTO } \\
\text { Designation No. }\end{array}$ & Results & Specification Limits \\
\hline \multirow{2}{*}{1} & Los Angeles abrasion $(\%)$ & & $6.5 \%$ & $\leq 10 \%$ \\
& After 100 revolutions & $\mathrm{T}-96$ & $28 \%$ & $\leq 40 \%$ \\
\hline 2 & After washing after 500 revolutions & & $\mathrm{T}-85$ & $\leq 5 \%$ \\
\hline 3 & Water absorption $(\%)$ & $\mathrm{T}-85$ & $2.576 \mathrm{~g} / \mathrm{cm}^{3}$ & - \\
\hline
\end{tabular}

One type of bituminous materials, Suez asphalt cement with 60-70 penetration grade, is used throughout the study. The properties of the asphalt cement used are presented in Table 3. The table shows that (60-70) penetration grade Suez asphalt cement has acceptable engineering properties for use as a binder according to Egyptian specifications [22]. Table 4 presents the Marshall properties at optimum bitumen content (OBC).

Table 3. Properties of used bitumen.

\begin{tabular}{ccccc}
\hline Test No. & Test & $\begin{array}{c}\text { AASHTO } \\
\text { Designation No. }\end{array}$ & Results & $\begin{array}{c}\text { Specification } \\
\text { Limits }\end{array}$ \\
\hline 1 & Penetration, $0.1 \mathrm{~mm}$ & $\mathrm{~T}-49$ & 64 & $60-70$ \\
2 & Softening point, $25^{\circ} \mathrm{C}$ & $\mathrm{T}-53$ & 52 & $45-55$ \\
3 & Flash point, $25^{\circ} \mathrm{C}$ & $\mathrm{T}-48$ & +270 & $>250$ \\
4 & Kinematic viscosity, cst & $\mathrm{T}-201$ & +345 & $>320$ \\
5 & Ductility, cm & $\mathrm{T}-51$ & 130 & $\geq 95$ \\
\hline
\end{tabular}


Table 4. Marshall properties at optimum bitumen content (OBC).

\begin{tabular}{cccc}
\hline Test No. & Test & Results & Specification Limits \\
\hline 1 & Stability $(\mathrm{kg})$ & 1120 & $900 \mathrm{~kg}(\mathrm{~min})$ \\
2 & Flow $(\mathrm{mm})$ & 3.15 & $2-4 \mathrm{~mm}$ \\
3 & Stiffness $(\mathrm{kg} / \mathrm{mm})$ & 389 & $300-500 \mathrm{~kg} / \mathrm{mm}$ \\
4 & Bulk specific gravity, $\mathrm{Gmb}\left(\mathrm{g} / \mathrm{cm}^{3}\right)$ & 2.311 & - \\
5 & \%Air voids in total mix $(\mathrm{Va})$ & 4.4 & $3-5 \%$ \\
\hline
\end{tabular}

Lime stone dust was used as control mineral filler in the HMA mixture with $2.75 \mathrm{~g} / \mathrm{cm}^{3}$ bulk specific gravity. In Table 5, the gradation of the mineral filler and the specification limits are presented.

Table 5. The gradation of mineral filler.

\begin{tabular}{ccc}
\hline Sieve Size & Gradations of Used Aggregates & Specification Limits \\
\hline No. 30 & 100 & 100 \\
No. 50 & 100 & - \\
No. 100 & 92 & $85 \%(\mathrm{~min})$ \\
No. 200 & 80 & $65 \%(\mathrm{~min})$ \\
\hline
\end{tabular}

The steel fiber used in pothole patching of surfaces was obtained from "Nassar Group" Industrial Company, Cairo, Egypt. Table 6 presents the specification of the steel fiber used in pothole patching.

Table 6. Properties of steel fiber.

\begin{tabular}{ccccc}
\hline Diameter $(\mathbf{m m})$ & Length $(\mathbf{m m})$ & $\begin{array}{c}\text { Aspect } \\
\text { Radio }\end{array}$ & $\begin{array}{c}\text { Tensile } \\
\text { Strength (MPa) }\end{array}$ & Material \\
\hline 0.6 & 25 & 58 & $\geq 1100$ & Low carbon steel bar \\
\hline
\end{tabular}

\subsubsection{Materials of Subbase Layer}

The aggregates that were used as the subbase material were from "ATAKA" quarry, Suez Governorate (Suez, Egypt). Table 7 presents the properties of the aggregate used, according to the Egyptian specifications for subbase layers. Table 8 presents the gradation of aggregates of the subbase layer.

Table 7. Aggregates characteristics of subbase layer.

\begin{tabular}{ccccc}
\hline Test No. & Test & $\begin{array}{c}\text { AASHTO } \\
\text { Designation No. }\end{array}$ & Results & Specification Limits \\
\hline 1 & Los Angeles abrasion $(\%)$ & & $7 \%$ & $\leq 10 \%$ \\
After 100 revolutions & T-96 & $29 \%$ & $\leq 40 \%$ \\
\hline 2 & After washing after 500 revolutions & & $2.6 \%$ & $\leq 5 \%$ \\
\hline 3 & Wulk specific gravity $\left(\mathrm{g} / \mathrm{cm}^{3}\right)$ & $\mathrm{T}-85$ & $2.77 \mathrm{~g} / \mathrm{cm}^{3}$ & - \\
\hline
\end{tabular}


Table 8. Aggregate gradation of subbase layer.

\begin{tabular}{ccc}
\hline Sieve Size & Gradations of Used Aggregates & Specification Limits (4C) \\
\hline In & 100 & 100 \\
1 & 100 & $80-100$ \\
$1 / 4^{\prime \prime}$ & 84 & - \\
$3 / 8^{\prime \prime}$ & 71 & $60-80$ \\
No. 4 & 20 & $48-65$ \\
No. 8 & 2 & $35-50$ \\
\hline
\end{tabular}

\subsection{Experimental Program}

In the first stage of this study, slabs were cast to simulate the surface of a road. One of them was without defects (A0) and the other contained potholes made by drilling in the middle of the slab in a circular shape with a $150 \mathrm{~mm}$ diameter and different depths $(35,50$ and $70 \mathrm{~mm})$; other slabs contained potholes at the same position in a square shape with $150 \mathrm{~mm} \times 150 \mathrm{~mm}$ dimension at the same depths, as shown in Figure 1. In the second stage, the potholes were patched with two methods: the first method with hot mix asphalt only and the second method with hot mix asphalt and 5\% steel fiber per volume of asphalt mix at different depths. Table 9 summarizes the prepared slabs to simulate the surface of the road. The steps of patching circular potholes are shown in Figure 2.

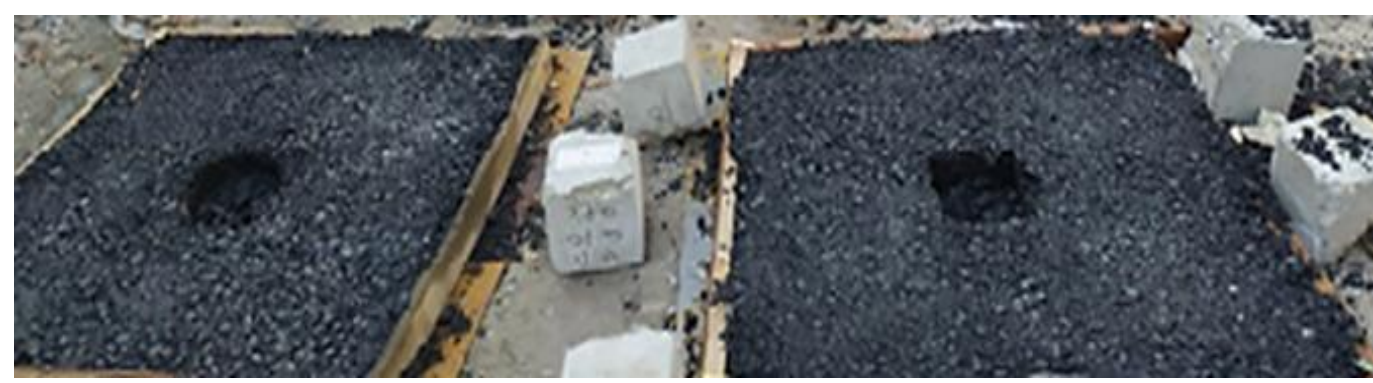

Figure 1. Shape of defects.

Table 9. Experimental program carried out on slabs.

\begin{tabular}{ccccc}
\hline Name & Dimensions (cm) & Depth of Patching $\mathbf{( c m )}$ & Shape of Patching & Patching \\
\hline A0 & $80 \times 80 \times 7$ & - & Without defects & - \\
A1 & $80 \times 80 \times 7$ & 3.5 & Circular & - \\
A2 & $80 \times 80 \times 7$ & 5.0 & Circular & - \\
A3 & $80 \times 80 \times 7$ & 7.0 & Circular & RC + hot mix asphalt \\
A4 & $80 \times 80 \times 7$ & 3.5 & Circular & RC + hot mix asphalt \\
A5 & $80 \times 80 \times 7$ & Circular & RC mix asphalt \\
A6 & $80 \times 80 \times 7$ & 5.0 & Circular & Circular \\
A7 & $80 \times 80 \times 7$ hot mix asphalt $+5 \%$ steel fiber \\
A8 & $80 \times 80 \times 7$ & 7.0 & Circular & RC + hot mix asphalt $+5 \%$ steel fiber \\
A9 & $80 \times 80 \times 7$ & 3.5 & Circular & RC + hot mix asphalt $+5 \%$ steel fiber \\
B1 & $80 \times 80 \times 7$ & 5.0 & Square & - \\
B2 & $80 \times 80 \times 7$ & 7.0 & Square & - \\
B3 & $80 \times 80 \times 7$ & 3.5 & Square & - \\
B4 & $80 \times 80 \times 7$ & 5.0 & Square & RC + hot mix asphalt \\
B5 & $80 \times 80 \times 7$ & 7.0 & Square & RC + hot mix asphalt \\
B6 & $80 \times 80 \times 7$ & 3.5 & Square & RC + hot mix asphalt \\
B7 & $80 \times 80 \times 7$ & 5.0 & Square & RC + hot mix asphalt $+5 \%$ steel fiber \\
B8 & $80 \times 80 \times 7$ & 7.0 & Square & RC + hot mix asphalt $+5 \%$ steel fiber \\
B9 & $80 \times 80 \times 7$ & 3.5 & Square & RC + hot mix asphalt $+5 \%$ steel fiber \\
\hline
\end{tabular}



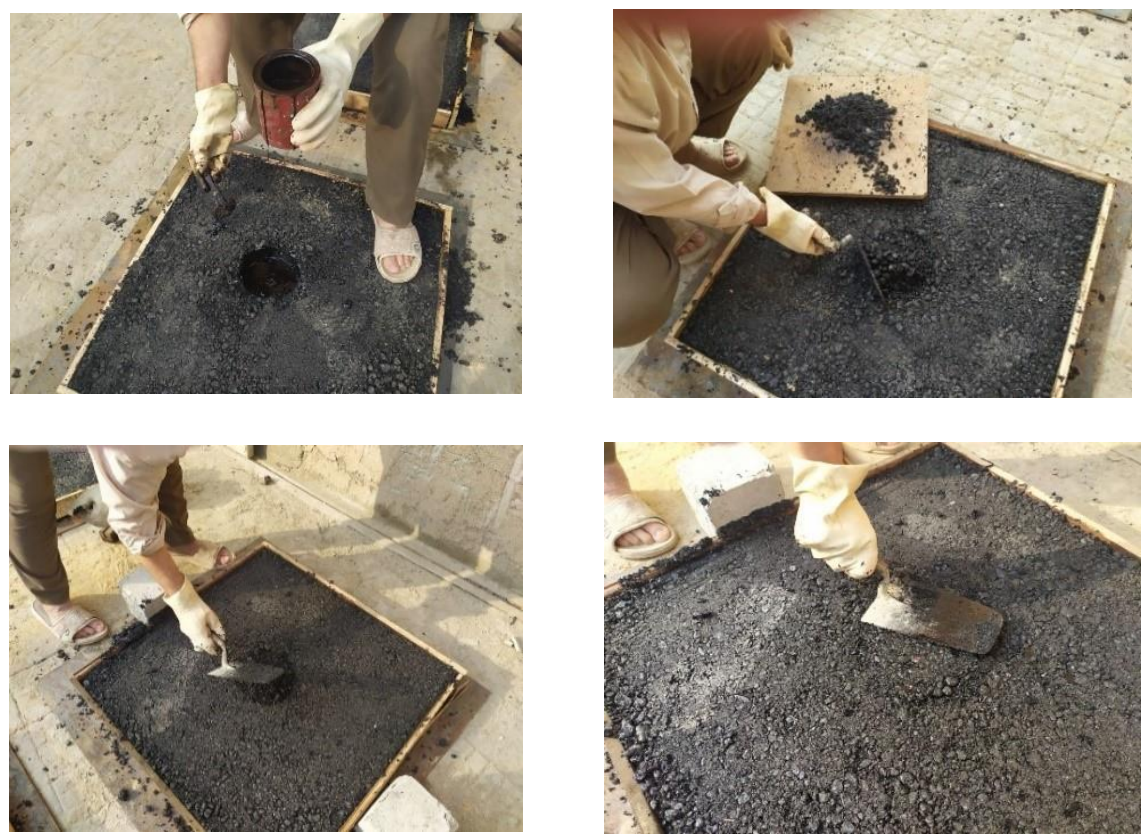

Figure 2. Steps of patching circular potholes.

The compaction process was accomplished using a $200 \mathrm{~kg}$ roller (Figure 3) to simulate a real compaction process. This roller was used for the control slab and the other slabs (with the dimensions of $800 \mathrm{~mm} \times 800 \mathrm{~mm} \times 70 \mathrm{~mm}$ ) to avoid relative errors due to compaction. The asphalt slab roller compactor applies loads that are equivalent to those of full-scale compaction equipment. Thus, this method can produce asphalt samples that are similar to materials used in actual highway pavements.

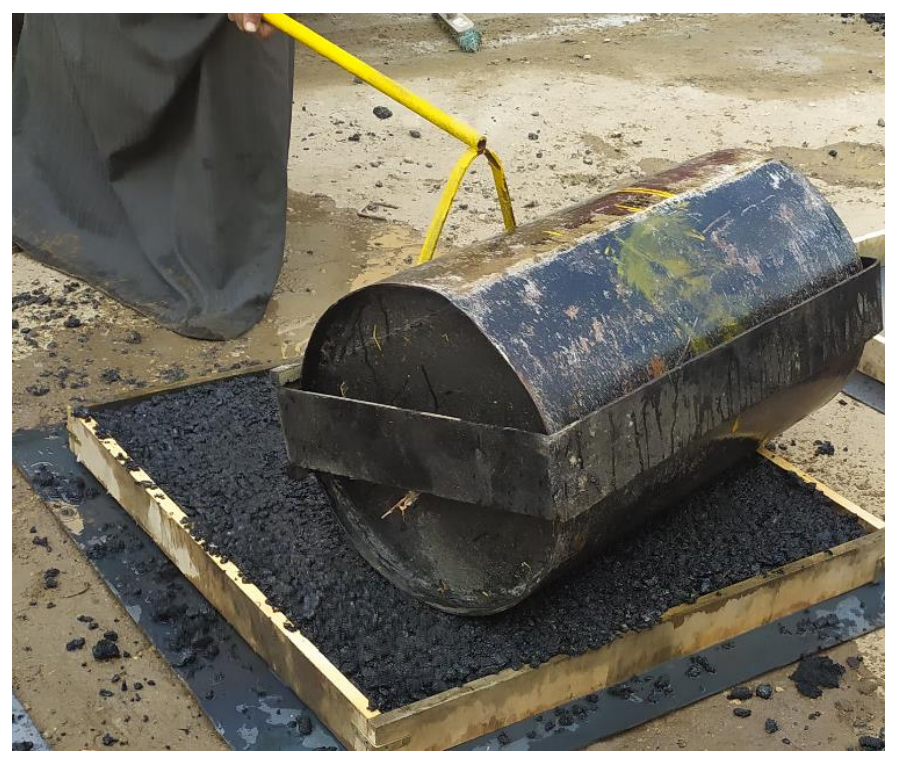

Figure 3. Roller compactor.

In the third stage, slabs were tested using the loading frame at the interface joint between the new and old pavement parts at different depths and shapes of patching with and without steel fiber additive.

\subsection{Loading Frame Test}

The loading frame test was conducted on slabs according to the Egyptian code [22]. The test setup consisted of a rigid steel frame supported on a laboratory rigid floor as 
shown in Figure 4. The load was applied using a hydraulic jack of $100 \mathrm{t}$ capacity connected to an electrical pump which provided oil pressure. The load was applied and measured using load cells connected to the data acquisition system to measure load and strain. The reading was recorded and saved in a Microsoft Excel spreadsheet. The load was increased linearly until failure. A rigid steel frame was used to distribute a concentrated load at the edge of the contact area $(6 \mathrm{~cm} \times 6 \mathrm{~cm} \times 4 \mathrm{~cm})$ at the joint between the repaired pothole and the remaining part of the slab, as shown in Figure 5.

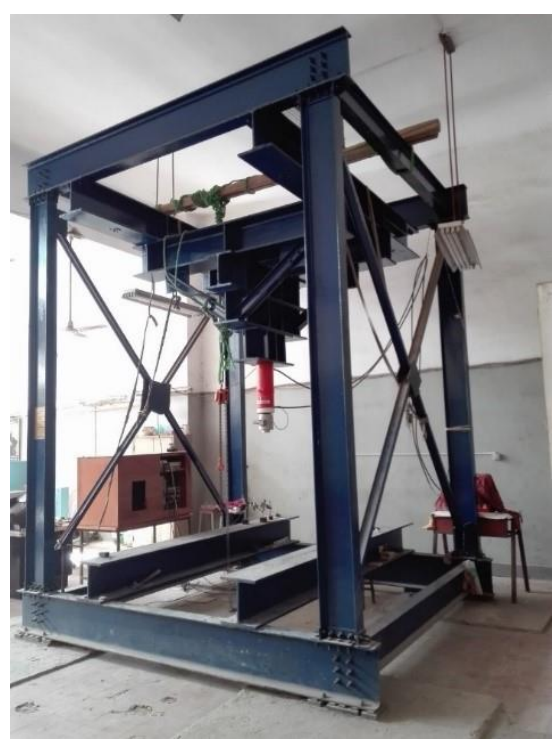

Figure 4. Rigid steel frame.

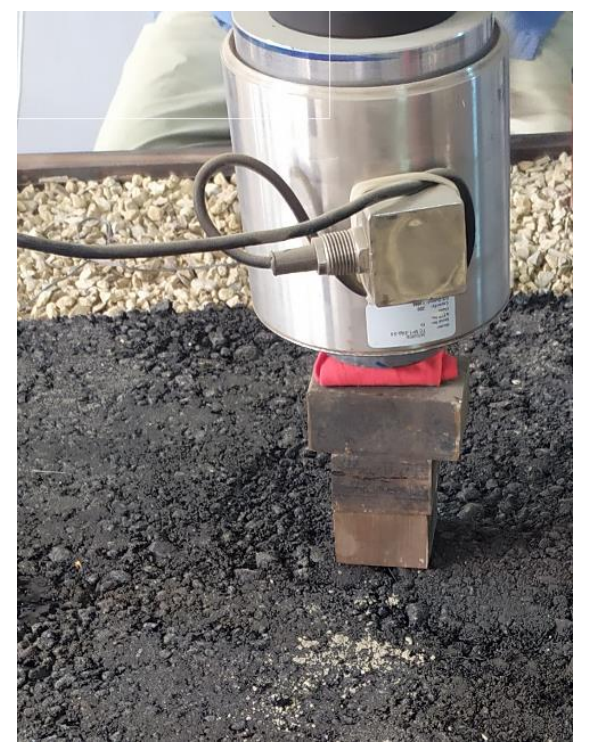

Figure 5. Location of a concentrated load of rigid steel frame.

Strain gauges were installed in each specimen to measure the strain during loading at the edge of the contact area of crack and slab. The properties of the strain gauges used are presented in Table 10.

For each test, the specimen was aligned inside the testing frame and strain gauges were connected to the data acquisition system at the joint between the repaired pothole and the remaining part of the slab. During the test, the initiation and propagation of cracks were marked after each load increment up to failure in order to understand the behavior of 
the tested specimens, as shown in Figure 6. Crack loads, ultimate failure load and strain were recorded.

Table 10. The properties of strain gauges used.

\begin{tabular}{cc}
\hline Gauge length & $6 \mathrm{~mm}$ \\
Gauge factor & $2.12 \pm 1 \%$ \\
Gauge resistance & $120.3 \pm 5 \Omega$ \\
Transverse sensitivity & $0.1 \%$ \\
\hline
\end{tabular}
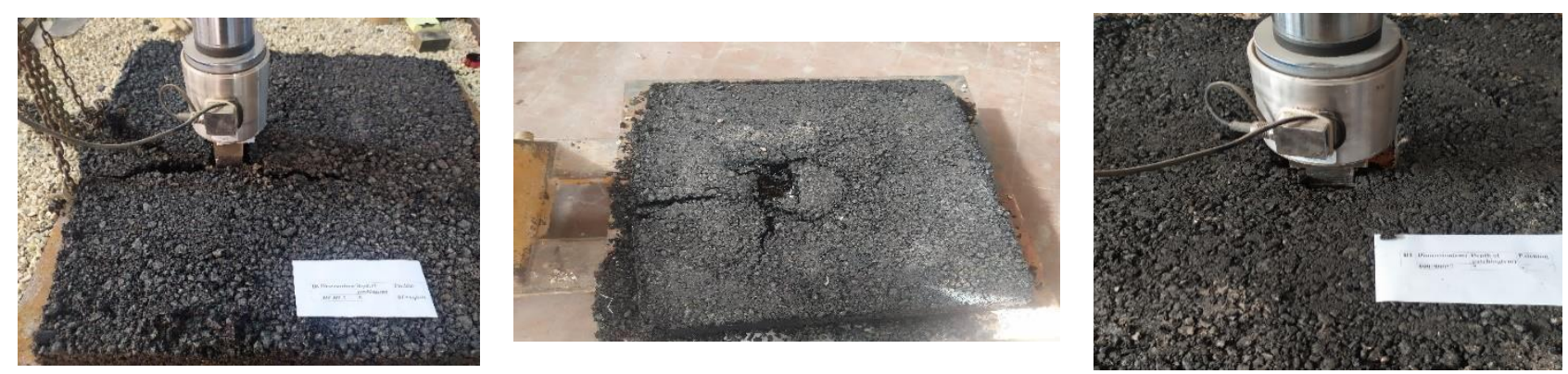

Figure 6. Marked potholes after loading.

\subsection{Finite Element Analysis Modeling}

Numerical analysis has been widely used to predict the behavior of pavement systems using the Finite Element Method (FEM) [23-26], which does not require a formulation or function of the solution. Stress, strain and displacement calculations were performed using the code ABAQUS [27,28].

The model used here contains two layers. The first layer is a surface with a size of $800 \mathrm{~mm} \times 800 \mathrm{~mm} \times 70 \mathrm{~mm}$ and was built from hot mix asphalt. The second layer is a container with a size of $1200 \mathrm{~mm} \times 1200 \mathrm{~mm} \times 650 \mathrm{~mm}$. This container is a simulated subbase of the road and was built from aggregates. The subbase was used to simulate a road layer, fix and support the surface layer and also to study the actual behavior of the subbase. The wire layer had distress in the form of circular and square potholes. Simulated circular potholes were made by cutting $150 \mathrm{~mm}$ of asphalt out in the middle of the slabs at different depths $(35,50$ and $70 \mathrm{~mm})$. Simulated square potholes were made by cutting $150 \mathrm{~mm} \times 150 \mathrm{~mm}$ of asphalt out in the middle of the slabs at the same depths. Figure 7 shows the meshing of the model.

The boundary conditions for the four sides of the base were roller supports, so there was no horizontal displacement. The bottom surface of the base layer was prevented from axial movements in the three directions and was completely fixed, as shown in Figure 8. Table 11 shows the mechanical properties of pavement layers.

Table 11. Mechanical properties of pavement layers.

\begin{tabular}{cccc}
\hline Layer & Density (N/mm $\left.\mathbf{m}^{\mathbf{3}}\right)$ & Modulus of Elasticity (E) (MPa) & Poisson's Ratio (v) \\
\hline Wiring layer & 2.24 & 2700 & 0.35 \\
\hline Base layer & 2.08 & 530 & 0.37 \\
\hline Patching Material & Density & Modulus of Elasticity (E) & Poisson's Ratio (v) \\
\hline HMA & 2.24 & 2700 & 0.35 \\
\hline HMA + steel fiber & 2.47 & 3700 & 0.33 \\
\hline
\end{tabular}




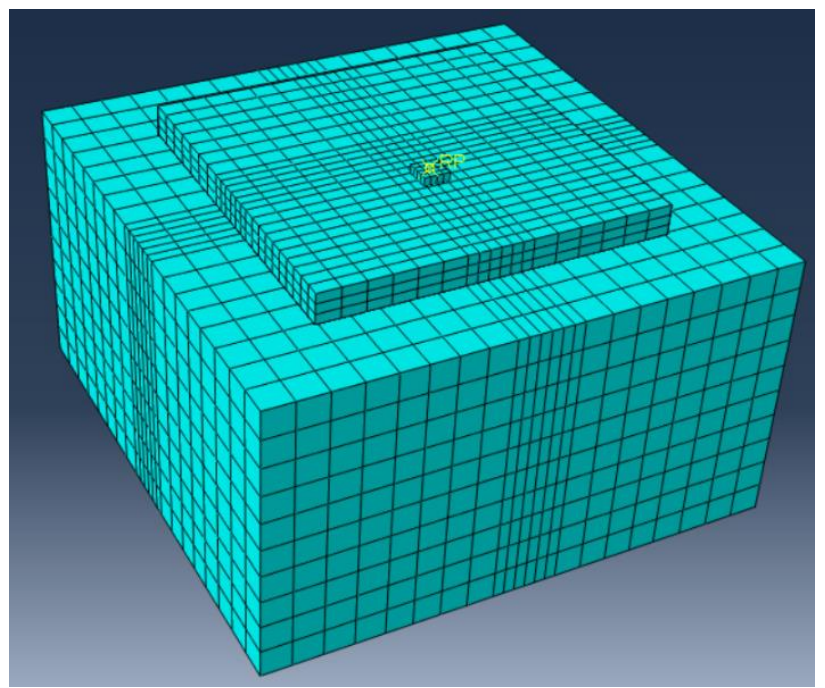

Figure 7. Meshing of the model.

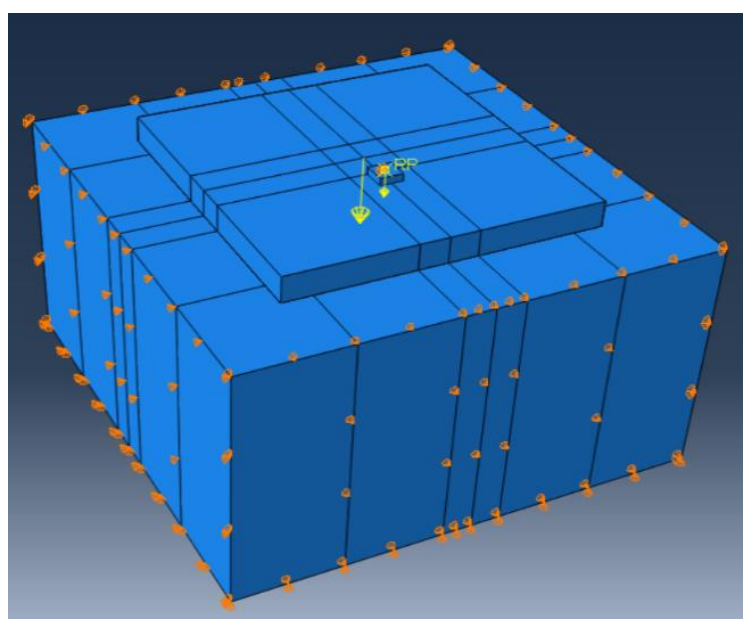

Figure 8. Boundary conditions of the model.

\section{Results and Discussion}

\subsection{Different Method of Patching at Different Depths}

Hot mix asphalt was used to patch circular and square potholes with steel fiber and without additives at different depths and shapes to identify the effects of these parameters on the bond between the joint of the repaired pothole and the remainder of the slab. Figure 9 shows the relation between load and strain before patching to compare the laboratory and analysis results for circular and square potholes without patching. Generally, there is good agreement between the laboratory and analysis results of the max load and max strain. It can be observed that circular-patched slabs (A1, A2, A3) gave lower max load and max strain than square-patched slabs (B1, B2, B3), and the same as the original slab A0 without defects. Slabs of the same shape have approximately the same max load and max strain. This means that the shape of the pothole has a more pronounced effect on pothole progress than the depth. 


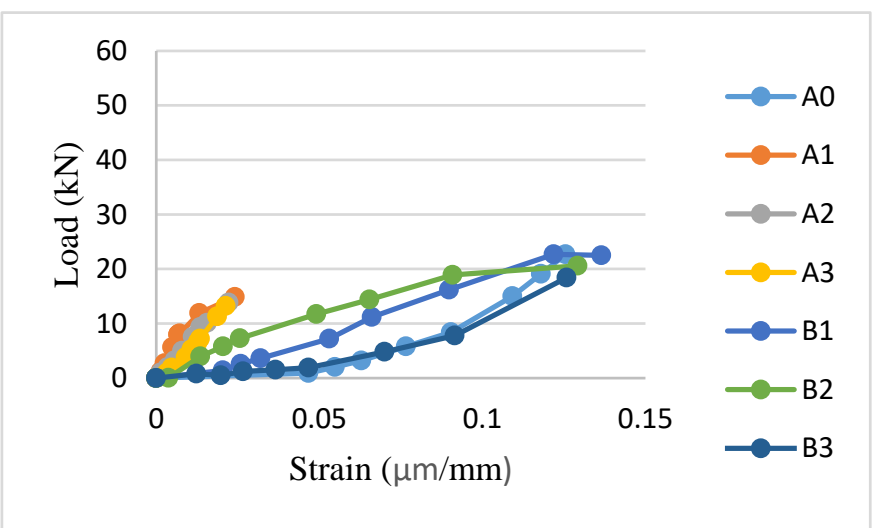

(a)

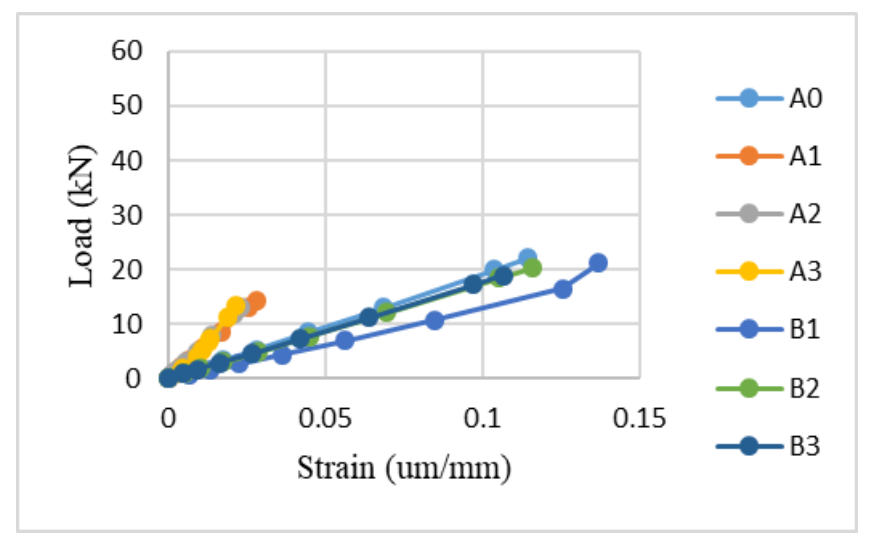

(b)

Figure 9. Strain comparison for failure load of circular and square potholes without patching. (a): experimental results. (b): numerical simulation results.

Figure 10 shows the relation between load and strain for circular and square potholes patched with asphalt only. It can be observed that circular-patched slabs (A6, A5, A4) gave closer max load and max strain compared to square-patched slabs (B6, B5, B4) but lower than all of them. This means that the depth of patching in case of circular patching shape has no effect on the bonding at the joint between the repaired pothole and the remaining part of the slab. In the case of the square patching shape, the bonding at the interface joint increased with increasing the patching depth, and all of them were higher than the circular-patched slabs. Again, the experimental and numerical results are approximately the same.

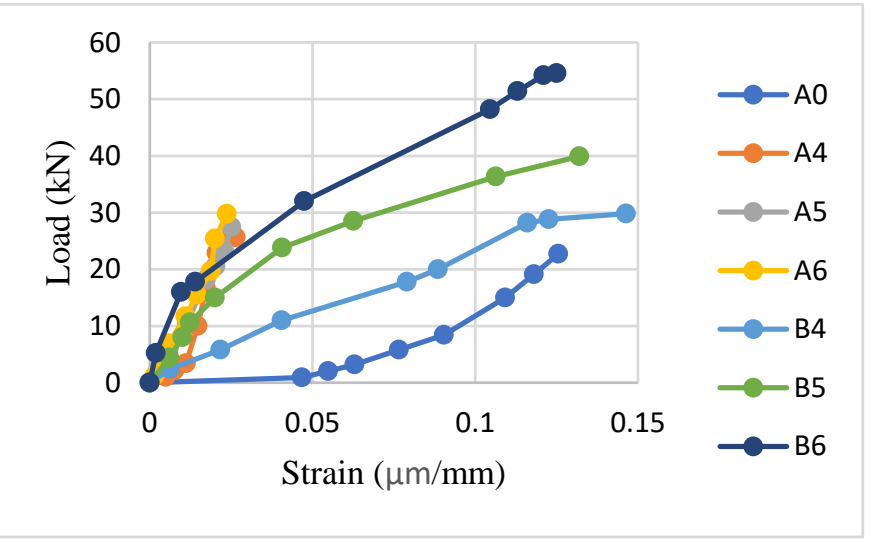

(a)

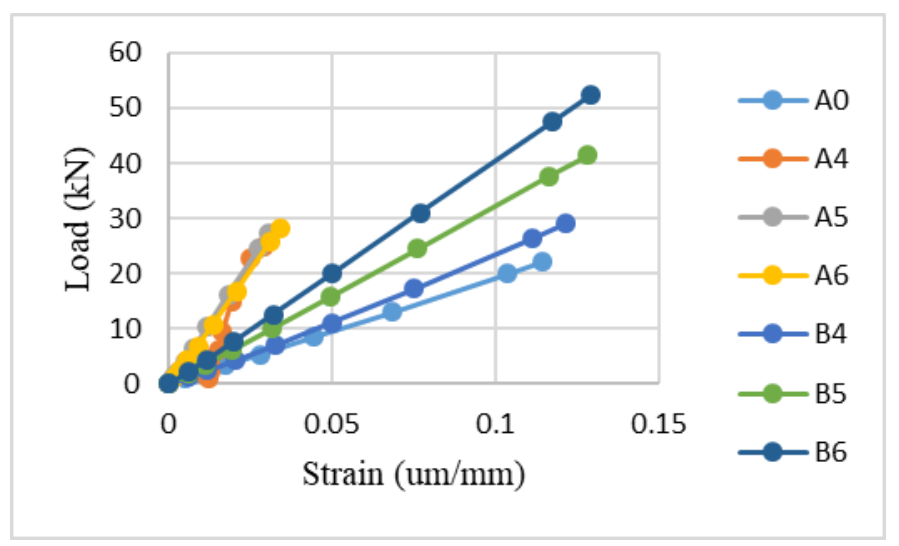

(b)

Figure 10. Strain comparison for failure of circular and square pothole patching with asphalt at the interface joint. (a): Experimental results. (b): Numerical simulation results.

Figure 11 illustrates the relation between load and strain to compare the laboratory and analysis results for circular and square pothole patching with asphalt and steel fiber. The addition of $5 \%$ steel fiber by volume to the asphalt patching material slightly improved the bonding at the interface joint of the circular-patched slabs but the three studied depths are still close. Regarding the square-patched slabs, bonding at the interface joint of the slab patched at the least depth $(3.5 \mathrm{~cm})(\mathrm{B} 4)$ slightly improved and the one at the depth of $5 \mathrm{~cm}$ (B5) was unaffected. The bonding of the slab pathed at $7 \mathrm{~cm}$ (B6) decreased. This may be explained by the fact that steel fibers increase the surface stability of the pavement, but as the depth increases, the amount of the used material increases, and the compression level decreases; consequently, the stability decreases [20]. So when the depth 
of patching decreased in the case of the square-patched slabs, the bonding at the interface joint increased.

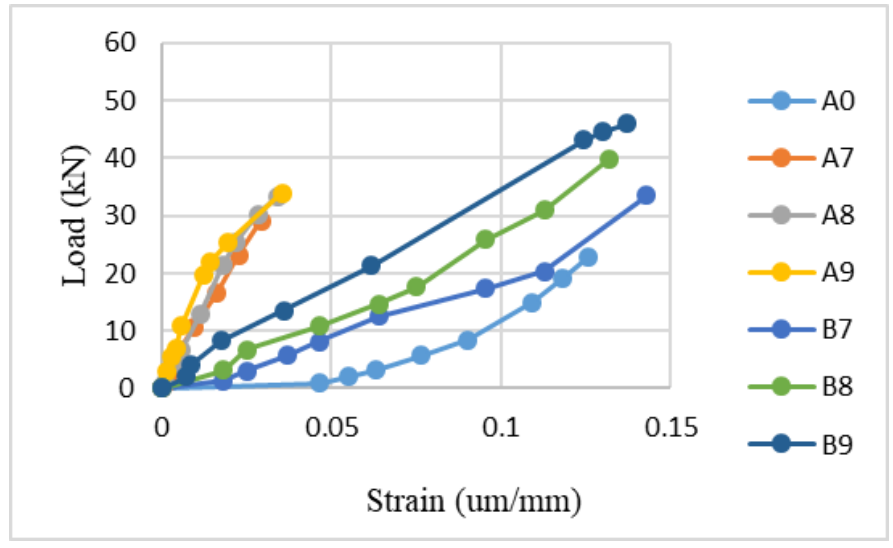

(a)

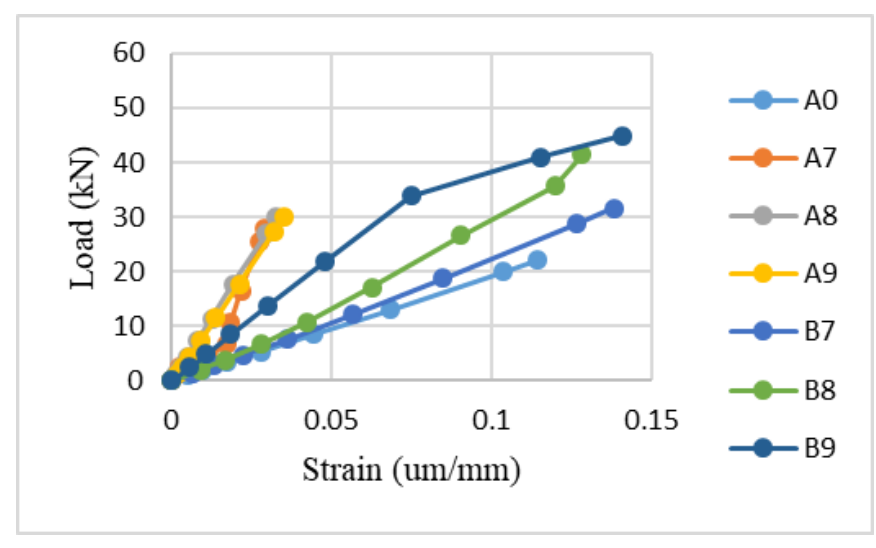

(b)

Figure 11. Strain comparison for failure load of circular and square pothole patching with asphalt and steel fiber at the interface joint. (a): Experimental results. (b): Numerical simulation results.

\subsection{Comparison between Laboratory Max Load and FEA Max Load}

A comparison of the max values of load for the nineteen tested specimens obtained experimentally and analytically is presented in Table 12. Generally, there is good agreement between the experimental and numerical maximum loads with a mean value of $4.3 \%$ difference. It can be observed that specimens with square potholes (B7, B8, B9) in all cases give closer max load compared to circular potholes (A7, A8, A9). Slab B9 increased the max load compared to slab A0 by a mean value $61.7 \%$ for experimental and $61.58 \%$ for numerical due to steel fiber, which increases the failure load of slabs.

Table 12. Comparison between max load results of the nineteen tested specimens.

\begin{tabular}{cccc}
\hline Sample & Max Load Exp. (kN) & Max Load FEA (kN) & Difference (\%) \\
\hline A0 & 22.70 & 22.00 & 3.08 \\
A1 & 14.84 & 14.20 & 4.31 \\
A2 & 13.81 & 13.15 & 4.78 \\
A3 & 13.20 & 12.99 & 1.61 \\
A4 & 25.60 & 24.90 & 2.73 \\
A5 & 27.40 & 27.175 & 0.82 \\
A6 & 29.77 & 28.25 & 5.11 \\
A7 & 29.17 & 27.92 & 4.30 \\
A8 & 33.20 & 29.85 & 10.10 \\
A9 & 34.00 & 29.92 & 12.00 \\
B1 & 22.50 & 21.12 & 6.11 \\
B2 & 20.60 & 20.26 & 1.67 \\
B3 & 18.40 & 18.88 & 2.59 \\
B4 & 29.80 & 28.98 & 2.77 \\
B5 & 39.90 & 41.44 & 3.87 \\
B6 & 54.56 & 52.34 & 4.06 \\
B7 & 33.60 & 31.57 & 6.05 \\
B8 & 46.00 & 44.88 & 2.44 \\
B9 & 59.20 & 57.27 & 3.26 \\
\hline
\end{tabular}




\subsection{Comparison between Laboratory Strain Load and FEA Max Strain}

A comparison of max values of strain for the nineteen tested specimens obtained experimentally and analytically are presented in Table 13. Generally, there is a good agreement between the experimental and numerical results.

Table 13. Comparison between max strain results of the nineteen tested specimens.

\begin{tabular}{ccc}
\hline Sample & Max Strain Exp. $(\mu \mathrm{m} / \mathbf{m m})$ & Max Strain FEA $(\mu \mathrm{m} / \mathbf{m m})$ \\
\hline A0 & 0.138 & 0.114 \\
A1 & 0.024 & 0.028 \\
A2 & 0.022 & 0.023 \\
A3 & 0.021 & 0.021 \\
A4 & 0.026 & 0.029 \\
A5 & 0.031 & 0.030 \\
A6 & 0.037 & 0.034 \\
A7 & 0.029 & 0.029 \\
A8 & 0.034 & 0.033 \\
A9 & 0.036 & 0.035 \\
B1 & 0.137 & 0.137 \\
B2 & 0.123 & 0.116 \\
B3 & 0.126 & 0.107 \\
B4 & 0.146 & 0.121 \\
B5 & 0.132 & 0.128 \\
B6 & 0.125 & 0.129 \\
B7 & 0.143 & 0.138 \\
B8 & 0.132 & 0.128 \\
B9 & 0.137 & 0.141 \\
\hline
\end{tabular}

\subsection{Comparison between Max Load and Deflection Using FEA}

The max value of a static load and the deflection results of the nineteen tested specimens for patching analytically using the ABAQUS software [28] are presented in Table 14. It can be observed that the specimens with square potholes (B7, B8, B9) in all cases gave closer max load and max deflection compared to circular potholes (A7, A8, A9). The slab that had square patching with asphalt and steel fiber or asphalt only had a max failure load. Figure 12 shows the shape of the deflection.

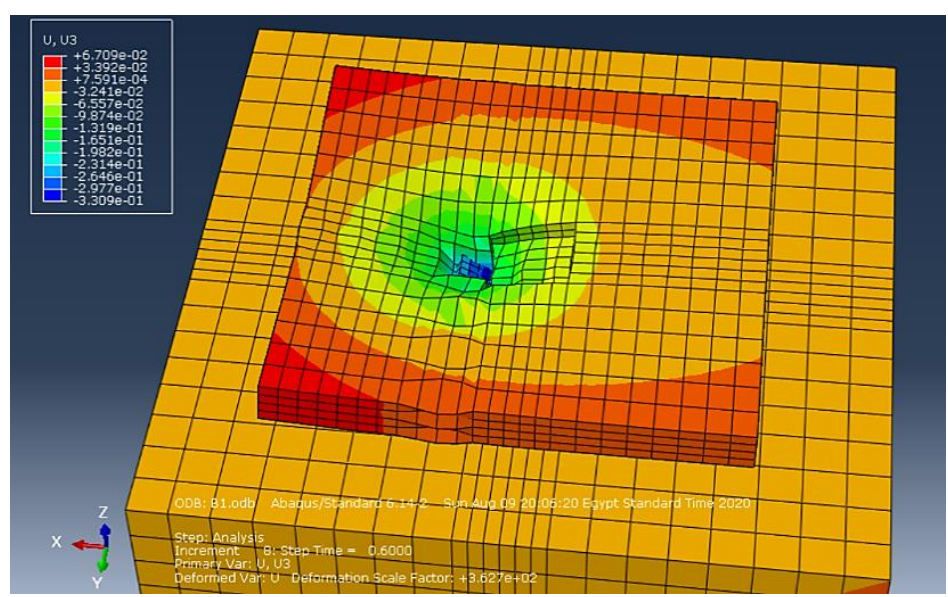

Figure 12. Shape of deflection. 
Table 14. Comparison between max load and deflection results of the nineteen tested specimens for patching analytically.

\begin{tabular}{ccc}
\hline Sample & Load $\mathbf{( k N )}$ & Deflection $(\mathbf{m m})$ \\
\hline A0 & 22.00 & 0.13 \\
A1 & 14.20 & 0.16 \\
A2 & 13.15 & 0.18 \\
A3 & 12.99 & 0.18 \\
A4 & 24.90 & 0.16 \\
A5 & 27.18 & 0.15 \\
A6 & 28.25 & 0.21 \\
A7 & 27.92 & 0.17 \\
A8 & 29.85 & 0.19 \\
A9 & 29.92 & 0.21 \\
B1 & 21.13 & 0.24 \\
B2 & 20.26 & 0.29 \\
B3 & 18.88 & 0.32 \\
B4 & 28.98 & 0.27 \\
B5 & 41.44 & 0.28 \\
B6 & 52.35 & 0.39 \\
B7 & 31.57 & 0.29 \\
B8 & 44.88 & 0.30 \\
B9 & 57.27 & 0.41 \\
\hline
\end{tabular}

\section{Conclusions}

In this study, the load failure at the joint interface of repaired potholes using HMA and HMA $+5 \%$ (volume) steel fiber was investigated at different conditions of pathing shape and depth using a rigid steel frame to study the stress strain behavior. The results were confirmed with numerical simulations using the finite element analysis software ABAQUS. The experimental results and numerical simulations were consistent. The results showed that the effect of the pothole's shape on its progress is more important than its depth. As for circular-patched potholes, the patching depth has no effect on the bonding at the joint interface in both cases of patching material. The use of HMA with 5\% (volume) steel fiber slightly increased the bonding at joint interfaces for circular-patched potholes. Regarding the square-patched potholes, increasing the patching depth increased the bonding at the interface joint using HMA, with better results than circular-patched ones. When HMA with $5 \%$ (volume) steel fiber was used with square-patched potholes, the bonding at the interface joint slightly improved at the lowest patching depth $(3.5 \mathrm{~cm})$ compared to the corresponding HMA-only case. But at deeper patching depths $(5$ and $7 \mathrm{~cm})$, there was no improvement, and bonding even decreased at the $7 \mathrm{~cm}$ depth.

Author Contributions: Conceptualization, M.S.E.; Methodology, V.A.K.; Writing-review \& editing, F.S.A. All authors have read and agreed to the published version of the manuscript.

Funding: This research received no external funding.

Institutional Review Board Statement: Not applicable.

Informed Consent Statement: Not applicable.

Data Availability Statement: All data presented in this study are available within this article.

Acknowledgments: The authors are thankful to the team work of General Authority for Roads, Bridges and Land Transport-GARBLT, Egypt.

Conflicts of Interest: The authors declare no conflict of interest. 


\section{References}

1. Jain, S.; Singh, B. Cold mix asphalt: An overview. J. Clean. Prod. 2021, 280, 100188. [CrossRef]

2. Kwon, B.J.; Kim, D.; Rhee, S.K.; Kim, Y.R. Spray injection patching for pothole repair using 100 percent reclaimed asphalt pavement. Constr. Build. Mater. 2018, 166, 445-451. [CrossRef]

3. Kuo, S.-S.; Carlo, L.; Kuenzel, C. Evaluation of Patching Materials and Placement Techniques for Rigid Pavements and Bridge Decks. 1999. Available online: https:/ / trid.trb.org/view / 649075 (accessed on 1 April 2021).

4. Asphalt Industry Alliance. Annual Local Authority Road Maintenance Survey; Asphalt Industry Alliance: Bristol, UK, 2020.

5. Saeed, F.; Rahman, M.; Chamberlain, D.; Collins, P. Asphalt surface damage due to combined action of water and dynamic loading. Constr. Build. Mater. 2019, 196, 530-538. [CrossRef]

6. Biswas, S.; Hashemian, L.; Hasanuzzaman, M.; Bayat, A. A study on pothole repair in Canada through questionnaire survey and laboratory evaluation of patching materials. Can. J. Civ. Eng. 2016, 43, 443-450. [CrossRef]

7. Dong, Q.; Huang, B.; Zhao, S. Field and laboratory evaluation of winter season pavement pothole patching materials. Int. J. Pavement Eng. 2014, 15, 279-289. [CrossRef]

8. Li, J.; Liu, J.; Zhang, W.; Liu, G.; Dai, L. Investigation of thermal asphalt mastic and mixture to repair potholes. Constr. Build. Mater. 2019, 201, 286-294. [CrossRef]

9. Liu, M.; Han, S.; Han, X.; Qi, X.; Dong, S. Microcapsule and polymer reinforcement techniques developed asphalt for use of pothole repairs in winter and rainy seasons. Cold Reg. Sci. Technol. 2019, 167, 102865. [CrossRef]

10. Dong, Q.; Dong, C.; Huang, B. Statistical analyses of field serviceability of throw-and-roll pothole patches. J. Transp. Eng. 2015, 141, 04015017. [CrossRef]

11. Dong, Q.; Huang, B.; Jia, X. Long-term cost-effectiveness of asphalt pavement pothole patching methods. Transp. Res. Rec. J. Transp. Res. Board 2014, 2431, 49-56. [CrossRef]

12. Hassn, A.; Aboufoul, M.; Wu, Y.; Dawson, A.; Garcia, A. Effect of air voids content on thermal properties of asphalt mixtures. Constr. Build. Mater. 2016, 115, 327-335. [CrossRef]

13. Obaidi, H.; Gomez-Meijide, B.; Garcia, A. On-site manufacture of hot mix asphalt using pellets that can be melted by induction energy. Powder Technol. 2019, 344, 58-67. [CrossRef]

14. Obaidi, H. Mechanical and sustainability assessment of induction heatable asphalt tiles and asphalt pellets in road maintenance. IOP Conf. Ser. Mater. Sci. Eng. 2020, 881, 012174. [CrossRef]

15. Liu, Q.; Schlangen, E.; Van De Ven, M.; Van Bochove, G.; Van Montfort, J. Evaluation of the induction healing effect of porous asphalt concrete through four point bending fatigue test. Constr. Build. Mater. 2012, 29, 403-409. [CrossRef]

16. Li, S.; Li, H. Repair technology for permanent asphalt pavement potholebased on microwave heating. Guangdong Highw. Commun. 2016, 146, 21-25.

17. Shi, N. Analysis on sawcut repair of rehabilitating worn asphalt pavement. J. Chongqing Jiaotong Univ. 2006, 25, 62-63.

18. Jiang, Z. Analysis on the application of circular grooves in pothole repairing of asphalt pavement. J. Highw. Transp. Res. Dev. Appl. Technol. 2017, 13, 131-132.

19. Li, L.; Huang, Y.; Shao, Z.; Ren, D. An experimental investigation on the repairing performance and fatigue life of asphalt pavement potholes with an inclined interface joint. Front. Mater. 2021, 7, 445. [CrossRef]

20. Serin, S.; Morova, N.; Saltan, M.; Terzi, S. Investigation of usability of steel fibers in asphalt concrete mixtures. Constr. Build. Mater. 2012, 36, 238-244. [CrossRef]

21. AL-Ridha, A.S.; Hameed, A.N.; Ibrahim, S.K. Effect of steel fiber on the performance of hot mix asphalt with different temperatures and compaction. Aust. J. Basic Appl. Sci. 2014, 8, 123-132.

22. Egyptian Code of Practice (ECP). Urban and Rural Roads, 1st ed.; Road Materials and Their Tests (Part Four); Egyptian Code of Practice (ECP): Cairo, Egypt, 2008.

23. Byzyka, J.; Rahman, M.; Chamberlain, D.A. Thermal analysis of hot mix asphalt pothole repair by finite-element method. $J$. Transp. Eng. Part B Pavements 2020, 146, 04020029. [CrossRef]

24. Yuan, K.Y.; Ju, J.W.; Yuan, W.; Yang, J.M. Numerical predictions of mechanical behavior of innovative pothole patching materials featuring high toughness, low-viscosity nano-molecular resins. Acta Mech. 2014, 225, 1141-1151. [CrossRef]

25. Vu, V.T.; Chupin, O.; Piau, J.M.; Hammoum, F. Finite element modelling of partially saturated asphalt specimens subjected to frost-Towards an explanation of winter potholes. Int. J. Pavement Eng. 2020, 1-13. [CrossRef]

26. Burge, L.M.; Tarhini, K.M.; Frederick, G.R. Investigation of Potholes in Concrete Slab Bridges. In Proceedings of the Eighth International Conference on Computing in Civil and Building Engineering (ICCCBE-VIII), Stanford, CA, USA, 14-16 August 2000; Volume 279, pp. 1054-1061.

27. Hibbit, D.; Karlsson, B.; Sorensen, P. Getting Started with ABAQUS, Version (6.5). 2005. Available online: https://classes. engineering.wustl.edu/2009/spring/mase5513/abaqus/docs/v6.5/books/gsa/default.htm (accessed on 1 April 2021).

28. Hibbitt, D.; Karlsson, B.; Sorenson, P. ABAQUS/Standard User's Manual, Version (6.2); Hibbitt, Karlsson \& Sorensen Inc.: Pawtucket, RI, USA, 2001. 